\title{
PRONAF NOS TERRITÓRIOS DA CIDADANIA DA BAHIA NOS GOVERNOS INSTITUÍDOS ENTRE 1999 E 2018
}

\author{
PRONAF IN THE TERRITORIES OF THE CITIZENSHIP OF BAHIA \\ IN THE GOVERNMENTS INSTITUTED BETWEEN 1999 AND 2018
}

\section{PRONAF EN LOS TERRITORIOS DE LA CIUDADANÍA DE BAHIA EN LOS GOBIERNOS INSTITUIDOS ENTRE 1999 Y 2018}

\author{
Cristiane Aparecida de Cerqueira ${ }^{1}$ \\ https://orcid.org/0000-0002-3667-3958 \\ Clesio Marcelino de Jesus ${ }^{2}$ \\ http://orcid.org/0000-0002-0249-5196 \\ Lessí Inês Farias Pinheiro ${ }^{3}$ \\ https://orcid.org/0000-0002-1424-8731
}

Submissão: 31/05/2020 / Aceito: 27/08/2020.

\begin{abstract}
Resumo
O crédito rural e o Pronaf foram instituídos pelo governo federal para apoiar o meio rural, enquanto os Territórios da Cidadania (TCs) foram criados para promover desenvolvimento rural em áreas com elevada presença de agricultores familiares. Neste período vários governos foram constituídos no Brasil, cada um com planos voltados ao meio rural conforme sua visão de Estado. Assim sendo, o trabalho analisa o acesso ao Pronaf nos nove TCs do estado da Bahia entre 1999 e 2018. Para tanto, a metodologia envolveu a pesquisa bibliográfica e documental, tendo como fonte o Banco Central do Brasil (Bacen) e o Instituto Brasileiro de Geografia e Estatística (IBGE). Os dados foram analisados por meio da estatística descritiva e do método comparativo, compreendendo o período entre o segundo mandato de Fernando Henrique Cardoso (FHC) e o segundo mandato de Dilma Roussef/Temer, cujos Planos Plurianuais revelam divergências ideológicas. Considerando os cinco governos, de modo geral, os valores dos contratos são baixos, existem significativas discrepâncias nos valores e nos números de contrato entre os territórios, e os TCs mais contemplados foram Semiárido Nordeste II, Velho Chico, Sisal e Sertão do São Francisco. Maior volume de recursos Pronaf deveria estar disponível aos Territórios Irecê, Chapada
\end{abstract}

\footnotetext{
1 Doutora em Economia pela Universidade Federal de Uberlândia (UFU). Docente do Departamento de Ciências Econômicas da Universidade Estadual de Santa Cruz (UESC). Ilhéus, BA, Brasil. E-mail: ccerqueira@uesc.br ;

2Doutor em Economia pela Universidade Federal de Uberlândia (UFU). Docente do Instituto de Economia e Relações Internacionais da Universidade Federal de Uberlândia (UFU). Uberlândia, MG, Brasil. E-mail: clesiomj@ufu.br ;

3Doutora em Serviço Social pela Pontifícia Universidade Católica do Rio Grande do Sul (PUCRS). Docente do Departamento de Ciências Econômicas da Universidade Estadual de Santa Cruz (UESC). Ilhéus, BA, Brasil. E-mail: lifpinheiro@uesc.br ;
} 
Diamantina e Itaparica, de elevada participação da agricultura familiar; diferente do Território Litoral Sul, que teve grande acesso aos recursos do Pronaf.

Palavras-Chave: Políticas Públicas; Crédito Rural; Pronaf, Estabelecimentos Familiares.

\begin{abstract}
The rural credit and Pronaf were instituted by the Brazilian federal government to support the rural environment, while the Territórios da Cidadania (TCs) Program were created with the goal to promote the rural development in depressed territories and with a elevated presence of farmers and their families. During this period many government were constituted in Brazil, each one of them with plans targeted at the rural environment according to their state point of view. Therefore, this paper analyzes the access to Pronaf in the nine TCs in the Bahia State between 1999 and 2018. Therefore, the methodology involves the bibliographic and documentary research, using the Banco Central do Brasil - Central Bank of Brazil - and IBGE (Brazilian Institute of Geography and Statistics) as source. The data were analyzed using descriptive statistics and the comparative method, comprising the period between the second term of office of Fernando Henrique Cardoso (FHC) and the second term of office of Dilma Roussef/Temer, whose Pluriannual Plans reveal ideological divergences. Considering the five governments, in general, the contract values are low, there are significant discrepancies in contract values and numbers between territories, and the TCs most contemplated were Semiárido Nordeste II, Velho Chico, Sisal and Sertão de São Francisco. Larger volume of Pronaf resources should be available to the Territórios Irecê, Chapada Diamantina and Itapiraca, which have a high participation of family farming; different from the Território Litoral Sul, which was greatly benefited.
\end{abstract}

Keywords: Public policies; Rural credit; Pronaf; Family Establishments.

\title{
Resumen
}

El gobierno federal instituyó el crédito rural y Pronaf para apoyar las áreas rurales, mientras que los territorios de ciudadanía (CT) se crearon para promover el desarrollo rural en territorios deprimidos y con una alta presencia de agricultores familiares. Durante este período, se constituyeron varios gobiernos en Brasil, cada uno con planes dirigidos al medio rural de acuerdo con su opinión estatal. Por lo tanto, el documento analiza el acceso a Pronaf en las nueve CT en el estado de Bahía entre 1999 y 2018. Para este fin, la metodología incluyó la investigación bibliográfica y documental, utilizando el Banco Central de Brasil (Bacen) y el Instituto Brasileño de Geografía y Estadística (IBGE) como fuente. Los datos se analizaron mediante estadística descriptiva y el método comparativo, que comprende el período entre el segundo término de Fernando Henrique Cardoso (FHC) y el segundo término de Dilma Roussef / Temer, cuyos Planes Plurianuales revelan divergencias ideológicas. Teniendo en cuenta a los cinco gobiernos, en general, los valores de los contratos son bajos, existen discrepancias significativas en los valores y números de los contratos entre territorios, y los CT más contemplados fueron Semiárido Nordeste II, Velho Chico, Sisal y Sertão do São 
Francisco. Mayor volumen de recursos Pronaf debería estar disponible para los territorios Irecê, Chapada Diamantina e Itaparica, con una alta participación de la agricultura familiar; diferente del territorio de la costa sur, que se benefició enormemente.

Palabras chave: Políticas públicas; Crédito rural; Pronaf, establecimientos familiares

\section{INTRODUÇÃO}

O Pronaf é uma importante política pública de crédito rural direcionada aos agricultores familiares em todo o país como parte integrante de ações para promoção do desenvolvimento rural. $\mathrm{Na}$ Bahia, um estado com forte presença de agricultores familiares, os recursos do Pronaf estão presentes com o objetivo de promoção desses agricultores, especialmente daqueles presentes nos recortes territoriais para desenvolvimento rural.

A política pública de crédito rural versa sobre a concessão de crédito à agricultura e à pecuária, a taxa de juros e condições de pagamento especiais. A institucionalização do crédito rural iniciou com o Penhor Agrícola, em 1885, e com o Penhor Rural e a Cédula Pignoratícia, ambas em 1937. Embora não tenha sido capaz de atender à necessidade nacional, efetivamente o crédito rural se estabeleceu em 1937 com a Carteira de Crédito Agrícola e Industrial (CREAI) (RAMOS; MARTHA JÚNIOR, 2010).

Mas a consolidação do crédito rural ocorreu com a criação do Sistema Nacional de Crédito Rural (SNCR), em $1965^{4}$, quando foi ampliada a rede bancária e o volume de recursos. Conforme o Manual de Crédito Rural (MCR), atualizado em julho de 2020, o crédito rural é a provisão nas modalidades custeio, investimento, comercialização e industrialização. Produtores rurais e cooperativas de produtores rurais podem ser beneficiários do crédito rural. Entretanto, o crédito rural via SNCR, historicamente beneficiou os médios e grandes produtores rurais ${ }^{5}$.

Para Bianchini (2015) diferente dos grandes produtores integrados ao mercado, historicamente a maioria dos pequenos produtores não teve acesso ao crédito rural. Essa situação levou a consolidação de médios e grandes produtores ligados ao agronegócio e a exclusão de boa parte dos pequenos agricultores. Como resultado da promulgação da

\footnotetext{
${ }^{4}$ O Crédito Rural foi instituído através da Lei no 4.829, de 5 de novembro de 1965.

${ }^{5}$ A classificação do produtor rural ocorre de acordo com a Receita Bruta Agropecuária Anual (RBA) ou a partir da receita estimada, da seguinte forma: i) pequeno produtor: até $\mathrm{R} \$ 415.000,00$; ii) médio produtor: acima de $\mathrm{R} \$ 415.000,00$ até $\mathrm{R} \$ 2.000 .000,00$; iii) grande produtor: acima de $\mathrm{R} \$ 2.000 .000,00$ (BACEN, 2020).
} 
Constituição de 1988 os pequenos agricultores se organizaram num novo arranjo institucional, que passou a reivindicar políticas de desenvolvimento rural. Assim, por causa de mobilizações dos pequenos produtores, da luta pela reforma agrária ancoradas no movimento sindical do campo, cujo movimento ficou conhecido como o "Grito da Terra Brasil”" e do apoio de instituições da sociedade civil e do poder público local, o governo federal, por meio da Resolução do Bacen n. 2.141 de 24 de agosto de 1995, institui o Programa Nacional de Fortalecimento da Agricultura Familiar (Pronaf), numa proposta de crédito diferenciado para o produtor familiar.

Então, o Pronaf foi construído como resultado de mobilizações "de baixo para cima”, de ações participativas e de diálogo entre os representantes dos agricultores familiares e gestores da política pública. O Decreto n. ${ }^{\circ} 1.946$ de 1996 instituiu o Pronaf para além do crédito, porque contemplou a pesquisa e a difusão de tecnologias, qualificação profissional, incentivando a participação e a descentralização, ao determinar a função de cada instância de governo, por meio dos Conselhos Municipais, Estaduais e Nacional (BIANCHINI, 2015).

Segundo o MCR são beneficiários do Pronaf os agricultores rurais que compõem as unidades familiares de produção rural que atendem, dentre outros, aos seguintes critérios: i) explorar a terra na condição de proprietário, posseiro, arrendatário, comodatário, parceiro, concessionário do Programa Nacional de Reforma Agrária (PNRA); ii) residir no estabelecimento ou em local próximo; iii) não deter área superior a 4 (quatro) módulos fiscais; iv) registrar, no mínimo, 50\% da renda bruta familiar originada de explorações do estabelecimento; v) registrar o trabalho familiar como predominante, utilizando mão de obra de terceiros de acordo com as exigências sazonais; vi) registrar renda bruta familiar anual de até $\mathrm{R} \$ 415.000,00$, exceto os benefícios sociais e os proventos previdenciários oriundos de atividades rurais (BACEN, 2020).

A partir de 2003 a construção das políticas públicas para o desenvolvimento rural voltou-se para a formação de territórios rurais em condições de maior vulnerabilidade. Visando o desenvolvimento territorial rural, Schejtman e Berdegué (2003) propõem uma arquitetura institucional em que o Estado e a sociedade civil atuem em conjunto, implementando programas e ações capazes de gerar transformações produtivas e institucionais, que compreendam o rural para além do setor agropecuário, desenvolvam 
capacitações e iniciativas a partir da identidade local, superem os problemas estruturais, como a desigualdade e pobreza.

Ainda em 2003 foi criado o Programa Território Rural (PTR), e em 2008 o Programa Territórios da Cidadania (PTC). A formação dos territórios procedeu com a reunião de municípios que apresentassem certa identidade, com base nas características socioeconômicas, geográficas e culturais, de modo a criar maior coesão necessária à promoção do desenvolvimento (BRASIL, 2008). Também exigia a participação de atores sociais nas diferentes esferas públicas e privadas, e da sociedade civil, numa gestão compartilhada com medidas de políticas públicas descentralizadas (ORTEGA, 2008).

O PTC deveria atuar, prioritariamente, em um grupo de municípios com maior nível de dificuldades socioeconômicas, grande concentração da pobreza rural, atendendo dentre outros, aos critérios de estar incorporado ao PTR, apresentar concentração de agricultores familiares e assentados da reforma agrária, populações quilombolas e indígenas (BRASIL, 2008). Como resultado desta política, na Bahia foram criados nove Territórios da Cidadania (TCs), com foco na agricultura familiar: Irecê, Velho Chico, Chapada Diamantina, Sisal, Baixo Sul, Sertão do São Francisco, Semiárido Nordeste II, Itaparica e Litoral Sul.

Há mais de duas décadas foi instituído o Pronaf; há mais de uma década foram organizados os TCs. Neste período vários governos também foram constituídos no Brasil, cada um com planos e programas voltados ao meio rural conforme sua visão de Estado. Por isto, este trabalho pretende responder à seguinte indagação: os TCs baianos com maior proporção de agricultores familiares foram os que mais acessaram os recursos do Pronaf entre os governos de Fernando Henrique Cardoso (FHC) e Dilma Rousseff?

Esta discussão é importante visto que o crédito rural é um dos instrumentos mais utilizados pelo governo para promoção do aumento de produção e produtividade no campo, e consequentemente para a sustentabilidade de crescimento econômico, que é parte integrante do desenvolvimento rural e territorial. Dessa forma, este trabalho visa oferecer e analisar as informações necessárias que auxiliem nas discussões e tomadas de decisões de órgãos normativos, colegiados territoriais, formuladores e gestores das políticas e programas públicos que tem a intenção de transformar a realidade da sociedade local, rural e territorial. 
Assim, a partir de reflexão teórica sobre a importância das políticas públicas agrárias e agrícolas, como objetivo central este trabalho analisa o acesso aos recursos do Pronaf nos TCs da Bahia nos governos instituídos entre 1999 e 2018. Especificamente, pretende-se: i) Discutir a visão de Estado sobre o crédito rural voltado à agricultura familiar nos planos dos governos constituídos; ii) Descrever as regras, condições de acesso e forma de operacionalização do Pronaf; iii) Discutir a distribuição dos recursos do Pronaf nos TCs.

Para tanto, a metodologia envolveu a pesquisa bibliográfica, a qual foi útil para avaliar os planos dos governos constituídos e descrever o funcionamento do Pronaf. Foi realizada pesquisa documental tendo como fonte o Banco Central do Brasil (Bacen) para obter informações sobre o número de contratos assinados e valores repassados (em $\mathrm{R} \$$ de 2018) do Pronaf em todas as modalidades. Ademais, foram utilizados dados do número e da área dos estabelecimentos agropecuários familiares dos Censos Agropecuários de 2006 e 2017, do Instituto Brasileiro de Geografia e Estatística (IBGE). Foi considerado o período entre o segundo mandato de FHC e o segundo mandato de Dilma Roussef/Temer, porque não foram encontrados dados para as gestões públicas anteriores a 1999 e posteriores a 2018. Tais dados foram analisados por meio da estatística descritiva e do método comparativo.

Deste modo, além dessa introdução o trabalho está dividido em cinco seções. A segunda apresenta as considerações acerca das especificidades do setor agropecuário e da importância dos programas públicos de crédito rural. A terceira avalia os Planos Plurianuais (PPAs) e a operacionalização do Pronaf nos mandatos entre 1999 e 2018. A quarta discute a distribuição dos recursos do Pronaf nos TCs baianos. Por fim, as considerações finais.

\section{POLÍTICAS PÚBLICAS DE CRÉDITO RURAL}

As características inerentes ao setor agropecuário incorrem em custos e abrem espaço para dificuldades que integram o ciclo produtivo até a introdução do produto no mercado. Logo, o Estado visa solucionar certos problemas que são implícitos à produção e comercialização do meio rural. Nesse sentido, as políticas públicas surgem de modo a corrigir determinadas falhas do setor que o produtor muitas vezes não está em condições de resolver (ARBAGE, 2012; ACCARINI, 1987). 
Existem duas versões de políticas direcionadas ao setor rural: as políticas agrárias e as políticas agrícolas. A política agrária visa corrigir a estrutura do sistema produtivo, enquanto a política agrícola visa orientar o comportamento dos agricultores quanto às questões ligadas ao processo produtivo. O governo pode fazer uso de instrumentos de política agrícola de modo a coordenar as ações dos produtores no sentido de trazer maior eficiência seja por meio de melhor uso da terra ou de implantação de novas tecnologias. Assim, alguns dos instrumentos de política agrícola utilizados são: crédito rural, assistência técnica e extensão rural, preços mínimos, comercialização, seguro rural, dentre outros (ARBAGE, 2012; ACCARINI, 1987).

A política creditícia é um dos instrumentos mais utilizado pelo governo, dado que seu processamento se efetiva rapidamente, a partir de viabilidade de recursos a agricultores visando o aumento da produção e da produtividade, o que faz dessa medida um instrumento de curto prazo. Para Accarini (1987, p.152), crédito rural é importante porque “[...] propicia maior flexibilidade para que o produtor coloque em prática decisões que lhe possibilitem explorar seu empreendimento rural de forma mais eficiente".

São três as finalidades do crédito rural: custeio, investimento e comercialização. $O$ crédito de custeio visa atender os custos da produção, financiando insumos utilizados no processo de produção como mudas, fertilizantes e defensivos. O crédito de investimento visa cobrir custos com insumos fixos, como máquinas, animais, tratores, colheitadeiras e construção de armazéns. Já o crédito de comercialização visa cobrir custos referentes às características do setor de descontinuidades da produção, preservando os preços dos produtos, em períodos que a oferta é concentrada e como forma de liquidação do crédito de custeio (ARBAGE, 2012; ACCARINI, 1987).

Tendo em vista as peculiaridades da produção agropecuária e as diferentes finalidades dos recursos do crédito rural, é possível afirmar que esse programa é fundamental para alavancar o setor primário da economia e, por consequência, os outros setores. Por isto, distintos governos subsidiam o crédito rural por meio de taxas de juros diferenciadas, com valores abaixo do mercado; e dentro do próprio setor também existe diferenciação nas taxas de juros seja o produtor classificado como agricultor familiar ou agricultor não familiar. 


\section{OS PLANOS PLURIANUAIS E A OPERACIONALIZAÇÃO DO PRONAF}

Os Planos Plurianuais e a operacionalização do Pronaf, entre o segundo governo de FHC (1999-2002) e o segundo governo de Dilma/Temer (2015-2018), serão aqui apresentados no intuito de salientar as diretrizes voltadas à disponibilidade de crédito rural para os estabelecimentos agropecuários do Brasil e, por consequência, do estado da Bahia.

O segundo governo do presidente FHC (1999-2002), intitulado social-democrata, adotou uma postura contraditória, porque muitas vezes apresentou princípios neoliberais. As “Diretrizes Estratégicas e Macro-objetivos do Plano Plurianual 2000-2003 - Avança Brasil" revelam tais incongruências. Dos 28 Macro-objetivos, por ordem de importância os 05 primeiros mostram o maior interesse na agricultura não familiar (BRASIL, 1999): i) Criar ambiente macroeconômico favorável ao crescimento sustentável; ii) Sanear as finanças públicas; iii) Elevar o nível educacional da população e ampliar a capacitação profissional; iv) Atingir US\$ 10 bilhões de exportação até 2002; v) Aumentar a competitividade do agronegócio. O plano apresenta como vigésima medida "Promover o desenvolvimento integrado do campo", proposta direcionada para o agricultor familiar (BRASIL, 1999)

Em relação ao agricultor familiar, para participar do Pronaf, instituído em 1996 (no primeiro governo de FHC), era obrigatório atender os seguintes critérios: a) explorar a terra enquanto proprietário, posseiro, arrendatário ou parceiro; b) não contratar empregado permanente; c) não possuir área superior a quatro módulos fiscais ${ }^{6}$; d) possuir o mínimo de $80 \%$ da renda bruta anual originária da atividade agropecuária ou extrativa; e) residir na propriedade ou em aglomerado urbano ou rural próximos (BIANCHINI, 2015).

No período 1999-2000, o Pronaf se ampliou, se estruturou, e passou a incluir os assentados, e a financiar atividades agropecuárias e não-agropecuárias (como turismo rural e o artesanato, por exemplo), em quatro grupos de beneficiários: A, B, C e D, da seguinte forma: i) Grupo "A": assentados da Reforma Agrária e beneficiários do Crédito Fundiário; ii) Grupo "B": agricultores com renda bruta familiar abaixo da linha de pobreza estabelecida

\footnotetext{
${ }^{6}$ Um módulo fiscal é medido, em hectares, com valor definido pelo Instituto Nacional de Colonização e Reforma Agrária (INCRA) para cada município, considerando as seguintes informações: levando-se em conta: (a) o tipo de exploração da agropecuária predominante; (b) a renda obtida na exploração predominante; (c) outras explorações importantes em função da renda gerada ou da área utilizada; (d) os critérios estabelecidos para propriedade familiar.(EMBRAPA, 2020).
} 
no ano, em $\mathrm{R} \$ 1.500,00$; iii) Grupo "C": agricultores familiares em transição, com baixo nível de capitalização e renda bruta familiar entre R $\$ 1.500,00$ e R\$8.000,00; iv) Grupo “D”: agricultores familiares mais capitalizados ou em início de capitalização, com renda bruta familiar entre $\mathrm{R} \$ 8.000,00$ e $\mathrm{R} \$ 27.500,00$ (BIANCHINI, 2015).

Assim, o Pronaf foi se consolidando para além do custeio, passando a cobrir o investimento, permitindo a ampliação da área plantada, da produção e da produtividade (por possibilitar acesso a tecnologias) de cerca de 50 alimentos, industrialização dos produtos agropecuários e fortalecimento de atividades não agrícolas (BRASIL, 2018).

Em 2000 o Pronaf foi transferido do Ministério da Agricultura, Pecuária e Abastecimento (MAPA) para o Ministério do Desenvolvimento Agrário (MDA) ${ }^{7}$. Neste período a taxa de juros variou entre $1 \%$ e $4 \%$ a.a., o Fundo de Amparo ao Trabalhador (FAT), o Orçamento Geral da União (OGU), Fundos Constitucionais, Bancos Cooperativos e as Exigibilidades Bancárias formaram as principais fontes de crédito. Porém, no segundo mandato de FHC, os contratos de Pronaf foram se reduzindo no país (BIANCHINI, 2015).

Diferente do governo FHC, o presidente Lula, em seu primeiro mandato (2003-2006), apresentou como prioridade as questões sociais, conforme pregava o "Plano Plurianual (2004-2007) - Brasil de Todos: participação e inclusão". A sua "Estratégia de desenvolvimento de longo prazo" foi decomposta em Megaobjetivos. Em relação ao espaço rural, o Megaobjetivo I atenta ao desafio de combater a fome e promover a segurança alimentar e nutricional. Algumas diretrizes relacionaram ganhos de produtividade, à produção e à comercialização de alimentos básicos, além de priorizar a aquisição de alimentos provenientes da agricultura familiar. O Plano também propunha efetivar a reforma agrária, recuperar os assentamentos existentes, fortalecer e consolidar a agricultura familiar, e promover o desenvolvimento sustentável do meio rural (BRASIL, 2003).

A partir de 2003 a agricultura familiar foi fortalecida com o Programa Vida Digna no Campo, do Programa Brasil Fome Zero e do Plano Safra da Agricultura Familiar. No âmbito do Programa Fome Zero merece destaque a criação do Programa de Aquisição de Alimentos (PAA) instituído pelo art. 19 da Lei $\mathrm{n}^{\circ}$ 10.696, de 02 de julho de 2003, que visava promover

${ }^{7}$ O MDA foi instituído em 14 de janeiro de 2000, por meio do Decreto n. 3.338 , composto pela Secretaria da Agricultura Familiar (SAF) e pelo Conselho Nacional do Desenvolvimento Rural Sustentável. 
o acesso à alimentação para famílias carentes e incentivar a agricultura familiar (ORTEGA; JESUS; SILVA SO,2006). Em relação ao Plano Safra, segundo Bianchini (2015, p.69-70):

\begin{abstract}
O Plano Safra da Agricultura Familiar nasceu e foi se consolidando, [...] fortemente centrado na política do crédito do Pronaf. A partir do Plano Safra 2003/2004, tem início uma visão clara de estratégia de governo, visando à promoção, ao fortalecimento e à consolidação da agricultura familiar para um rural sustentável, por meio do incremento do Pronaf Crédito e de um conjunto de novos instrumentos de políticas públicas. [...].
\end{abstract}

Entre 2003-2004 foram estabelecidas novas linhas e mais recursos para o Pronaf. Foi criado o Pronaf Alimentos, Pronaf Fome Zero no âmbito do Grupo B, Pronaf Mulher, Pronaf Jovem e o Pronaf Agroecologia. Entre 2004-2005 a poupança rural é coligada ao Pronaf, e houve ampliação dos recursos das exigibilidades bancárias e dos fundos constitucionais. A liberação dos recursos via cooperativas de crédito foi fortalecida e foi lançado o Pronaf Custeio da Agroindústria Familiar. Também foi direcionado o Programa Biodiesel para a Agricultura familiar.

Em 2006 foi editada a Lei 11.326, de 24 de julho de 2006, estabelecendo critérios para classificação do Agricultor Familiar, reconhecendo a importância dessa categoria e a melhor inserção nas políticas públicas para o setor. Entre 2006-2007 foram fortalecidos o Pronaf Custeio de Agroindústrias Familiares e de Comercialização (BIANCHINI, 2015).

No seu segundo mandato (2007-2010), o presidente Lula apresentou o Plano Plurianual (2008-2011), intitulado "Desenvolvimento com inclusão social e educação de qualidade". Neste plano foi ressaltada a importância do trabalho em parceria com o setor privado, governos estaduais e municipais, considerando o princípio territorial no planejamento, capaz de promover a superação das desigualdades sociais e regionais, o fortalecimento da coesão social e unidade territorial. Igualmente é possível identificar as contribuições capazes de modificar as condições do espaço rural, pois projetou iniciativas no intuito de gerar inclusão produtiva, renda e superação da pobreza a partir da estratégia de desenvolvimento sustentável de TRs e TCs (BRASIL, 2007).

Entre 2007-2008, dentre outras ações, foi reduzida a taxa de juros e criado o Pronaf Eco para financiar atividades sustentáveis; foi ampliado o limite da faixa etária para os beneficiários do Pronaf Jovem, para 29 anos. Entre 2008-2009 destaca-se a instituição do Pronaf Mais Alimentos, o fomento à mecanização, junção dos grupos C, D e E no Grupo V 
da "agricultura familiar", e as compras de produtos da agricultura familiar a partir do Programa Nacional da Alimentação Escolar (PNAE) (BIANCHINI, 2015).

Entre 2009-2010, ressalta-se o financiamento de veículos por meio do Pronaf Mais Alimentos. A Lei n. ${ }^{\circ} 11.947$ de 2009 obrigou que, no mínimo, 30\% dos recursos financeiros do Fundo Nacional de Desenvolvimento da Educação (FNDE), repassados ao PNAE, fossem destinados à compra dos produtos da agricultura familiar, consolidando o mercado para os agricultores. Ademais, foi criado o Selo da Agricultura Familiar, como outro instrumento de acesso a mercados (BIANCHINI, 2015).

No primeiro mandato de Dilma Roussef (2011-2014), o PPA 2012-2015 foi denominado "Plano Mais Brasil - mais desenvolvimento, mais igualdade, mais participação". No item intitulado "Projeto Nacional de Desenvolvimento", o plano ressalta a importância do aumento da produtividade (como resultado do avanço tecnológico), mas também destaca o valor do PTC. Neste sentido, o plano afirma que: "O apoio à agricultura familiar é fundamental, tendo em vista seu papel na produção de alimentos e regulação de seus preços, assim como na geração de renda no campo. Assim, é essencial que se preserve o ciclo da expansão do crédito [...]" (BRASIL, 2011, p. 79).

Mantendo os contrassensos, para alcançar o "Desenvolvimento produtivo" o PPA 2012-2015 propõe o fortalecimento dos Arranjos Produtivos Locais (APLs) visando a desconcentração da produção, mas também a internacionalização de empresas brasileiras, além da ampliação da indústria petroquímica nacional. No programa temático "Agropecuária sustentável, abastecimento e comercialização”, o plano apresenta como papel central as políticas e os instrumentos de ação do crédito rural (nas modalidades de custeio, investimento e comercialização). Na proposta de desenvolvimento regional propõe ampliar a estratégia da ação territorial que persegue o desenvolvimento como fruto das potencialidades percebidas pelo governo federal, estaduais, municipais, e sociedade civil (BRASIL, 2011).

Em relação ao Pronaf, entre 2010-2013 as principais medidas adotadas foram: maior apoio aos agricultores do Grupo B, ampliação dos limites de crédito (custeio, investimento em cooperativas, agroindústrias familiares, linha Mais Alimentos). Entre 2013-2014 houve mudanças na definição de agricultura familiar e nos juros; o limite de crédito foi ampliado. 
Entre 2014-2015 destaca-se a permanência das taxas de juros, a constituição do Pronaf Produção Orientada (para as regiões Norte, Nordeste e Centro-Oeste) e do Pronaf Mulher.

No segundo mandato de Dilma Rouseff (2015-2018) o Plano Plurianual 2016-2019 construído num espaço institucional de participação da sociedade civil, foi denominado “Desenvolvimento, produtividade e inclusão social", cuja intenção foi solidificar a conciliação entre crescimento econômico, distribuição da renda e inclusão social. Considerando a distribuição do crédito e demais fontes extraorçamentárias por Programas Temáticos, foi delineado $31 \%$ dos recursos para a agropecuária sustentável e apenas 5\% para fortalecimento e dinamização da agricultura familiar. O primeiro objetivo descrito vinculado ao Programa "Agropecuária Sustentável" foi ampliar a disponibilidade e o acesso aos recursos do crédito rural e a outras fontes de financiamento (BRASIL, 2015).

Entre 2015-2016, decidiu-se pelo fortalecimento da agroindústria familiar. Os agricultores familiares foram reclassificados em tais grupos: i) Grupo A: inclui os assentados da Reforma Agrária e Crédito Fundiário; ii) Grupo B: inclui os agricultores situados abaixo da linha de pobreza, com renda bruta familiar anual abaixo de $\mathrm{R} \$ 20$ mil reais; iii) Demais agricultores familiares: inclui aqueles com renda bruta familiar entre $\mathrm{R} \$ 20$ mil e $\mathrm{R} \$ 360$ mil por ano. O agricultor familiar passou a ser identificado em determinado grupo pelas informações apresentadas na Declaração de Aptidão ao PRONAF (DAP) (BIANCHINI, 2015). No período 2017-2018, do mandato Temer, muitas informações e relatórios simplesmente deixaram de ser acessíveis. Essa dificuldade é reflexo da extinção do Ministério do Desenvolvimento Agrário e a transformação numa simples secretaria, atualmente vinculada ao MAPA. O que dificultou uma análise mais aprofundada.

Assim sendo, é interessante observar que as políticas e ações de apoio à agricultura familiar apresentaram notável crescimento ao longo do período analisado (1999 a 2018). De um começo tímido no Governo de FHC, tais políticas e ações foram bastantes ampliadas nos dois Governos Lulas, mantiveram-se no primeiro Governo Dilma, quando apresentam redução ou eliminação no segundo Governo Dilma/Temer. No Caso do Pronaf, a trajetória no mesmo período foi de grande expansão. De acordo com dados apresentados por Bianchini (2015), o Pronaf aplicou R\$1,87 bilhões em 674 mil contratos na safra 1998/99, alcançou $\mathrm{R} \$ 2,3$ bi em 814 mil contratos na safra 2002/03. Enquanto na safra 2009/10 foram aplicados 
$\mathrm{R} \$ 12,6$ bilhões em 1.752 .988 contratos, ampliando o valor para $\mathrm{R} \$ 23,9$ bilhões em 1.899 .423 contratos na safra 2014/15.

Entretanto, essa expansão não se deu de forma proporcional pelas diferentes regiões do país, na verdade ela foi muito concentrada. Grisa, Wesz Junior e Buchweitz (2014), analisando a dinâmica de distribuição do Pronaf entre 1996 e 2012 afirmam que "trata-se historicamente de uma incidência desproporcional do programa entre as regiões brasileiras, com prevalência massiva da participação da região Sul nos recursos aplicados e, não raro, também nos contratos efetuados". Nesse sentido, Bianchini (2015) ao analisar os recursos do Pronaf na safra 2014/2015, demonstra que a Região Sul abocanhou 50\% dos recursos em $28 \%$ do total de contratos, seguido da Região Sudeste, que ficou com $20 \%$ dos recursos e $15 \%$ dos contratos. já a Região Nordeste aplicou 15\% do volume em $49 \%$ do total de contratos. Logo, o Pronaf no Nordeste é caracterizado pelo elevando número de contratos com baixo valor para atender as demandas do maior número de agricultores familiares entre as Grandes Regiões Brasileiras.

\section{DISTRIBUIÇÃO DOS RECURSOS DO PRONAF NOS TCS BAIANOS}

Nesta seção, inicialmente será descrito o percentual (do número e da área) dos estabelecimentos agropecuários familiares, com o intuito de identificar quais são os territórios que possuíam maior ou menor deste tipo de propriedade. Na sequência estão dispostos os dados do total de contratos assinados e de valores (em $\mathrm{R} \$$ ) repassados do Pronaf. Ademais, serão estimadas a média de contratos firmados e de valores (em $\mathrm{R} \$$ ) recebidos, por estabelecimento familiar e ou por contrato firmado, para facilitar a compreensão se a distribuição dos recursos foi realizada de acordo com as características dos territórios. Todas estas informações serão fornecidas em cada TC baiano, nos anos 2006 e 2017.

As características dos estabelecimentos agropecuários familiares, entre 2006 e 2017, permitem afirmar que os TCs do estado da Bahia são heterogêneos, não tanto quando se considera o número de estabelecimentos, mas quando são observadas as áreas ocupadas. Tanto em 2006, como em 2017, o Território Litoral Sul (TLS), se destaca com os menores percentuais de estabelecimentos familiares, $65,85 \%$ e 73,39\%, respectivamente, embora tenha sido o único que tenha experimentado aumento destes percentuais (TABELA 1). 
Tabela 1 - Percentual (do número e da área ocupada) dos estabelecimentos agropecuários familiares dos Territórios da Cidadania da Bahia em 2006 e 2017

\begin{tabular}{l|c|c|c|c}
\hline \multirow{2}{*}{$\begin{array}{c}\text { Divisão regional/ } \\
\text { Estabelecimentos familiares }\end{array}$} & \multicolumn{2}{|c|}{$\begin{array}{l}\text { Percentual de estabelecimentos } \\
\text { agropecuários familiares (\%) }\end{array}$} & \multicolumn{2}{c}{$\begin{array}{c}\text { Percentual da área ocupada } \\
\text { pelos estabelecimentos } \\
\text { agropecuários familiares (\%) }\end{array}$} \\
\cline { 2 - 5 } & 2006 & 2017 & 2006 & 2017 \\
\hline Brasil & 84,36 & 76,82 & 24,01 & 23,03 \\
Nordeste & 89,12 & 79,17 & 37,22 & 36,57 \\
Bahia & 87,42 & 77,79 & 33,62 & 32,15 \\
\hline Baixo Sul & 85,76 & 79,71 & 36,95 & 47,93 \\
Chapada Diamantina & 90,13 & 77,00 & 41,18 & 36,35 \\
Do Sisal & 88,56 & 77,94 & 51,82 & 49,51 \\
Irecê & 91,51 & 75,20 & 45,54 & 46,83 \\
Itaparica & 93,36 & 85,79 & 50,46 & 63,64 \\
Litoral Sul & 65,85 & 73,39 & 17,18 & 28,25 \\
Semi-árido Nordeste II & 90,24 & 80,67 & 48,15 & 49,22 \\
Sertão do São Francisco & 90,71 & 80,37 & 49,39 & 51,93 \\
Velho Chico & 88,57 & 83,79 & 44,19 & 42,50 \\
\hline
\end{tabular}

Fonte: IBGE (2020a; 2020b).

Nos demais TCs houve redução do percentual de estabelecimentos agropecuários familiares entre 2006 e 2017, por motivos variados, como êxodo rural, ampliação de atividades do agronegócio aliado a incorporação de estabelecimentos familiares, entre outros, porém eles permaneceram com maiores participações do que o TLS; e, em grande parte dos casos, os TCs apresentaram maiores percentuais que os verificados para a Bahia, Nordeste e Brasil. Em 2006, as propriedades familiares representavam mais de $90 \%$ do número de estabelecimentos nos territórios Irecê (91,51\%), Sertão do São Francisco (90,71\%), Semiárido Nordeste II (90,24\%) e Chapada Diamantina (90,13\%); em 2017 estes percentuais sofreram redução e passaram para 75,2\%, 80,37\%, 80,67\% e 77\%, respectivamente. Em 2017 os territórios Itaparica (85,79\%), Velho Chico (83,79\%), Semiárido Nordeste II (80,67\%) e Sertão do São Francisco (80,37\%) foram os de maiores percentuais de estabelecimentos familiares (TABELA 1).

Em relação à área ocupada pelos estabelecimentos agropecuários familiares, em 2006 e 2017, todos os TCs do estado da Bahia apresentaram percentuais menores que o número de estabelecimentos familiares. É possível entender que muitas eram as propriedades familiares, mas estas ocupavam percentuais menores da área total nos TCs baianos. O TLS mais uma 
vez se destaca por apresentar somente 17,18\% (em 2006) e 28,25\% (em 2017) da área ocupada pelos estabelecimentos do tipo familiar; percentuais semelhantes ao Brasil $(24,01 \%$ e $23,03 \%)$, mas inferiores ao do Nordeste $(37,22 \%$ e $36,57 \%)$ e da Bahia $(33,62 \%$ e $32,15 \%)$.

Por outro lado, em 2006 e em 2017, a área das propriedades familiares de alguns TCs ocupava a maioria da área total. Em 2006 os Territórios Sisal (51,82\%) e Itaparica (50,46\%) se destacavam. Em 2017, a área dos agricultores familiares era de 63,64\% no Território Itaparica e de 51,93\% no Território Sertão do São Francisco. Contudo, em 2006 o Território Sertão do São Francisco registrou 49,39\% da área pertencente a agricultores familiares; e, em 2017, os Territórios Sisal e Semiárido Nordeste II também possuíam importante participação dos proprietários familiares, 49,51\%, 49,22\%, respectivamente. Então, em 2006, o maior percentual de estabelecimentos familiares estava nos Territórios Irecê, Sertão do São Francisco, Semiárido Nordeste II e Chapada Diamantina; em 2017, estava nos Territórios Itaparica, Velho Chico, Semiárido Nordeste II e Sertão do São Francisco (TABELA 1).

A Tabela 2 apresenta o número de contratos assinados em cada TCs do estado da Bahia nos mandatos de FHC à Dilma/Temer, referente aos anos entre 1999 e 2018. Em geral, houve aumento significativo do número de contratos assinados do segundo governo de FHC para o primeiro governo Lula; todavia, no segundo governo Lula houve significativa redução do número de contratos firmados, que retornaram no primeiro e segundo governo Dilma.

No segundo governo de FHC (1999-2002) os Territórios que mais assinaram contratos Pronaf foram Velho Chico (40.753) e Semiárido Nordeste II (31.128), número muito superior aos demais territórios. No primeiro governo Lula (2003-2006) foi bastante ampliado os contratos firmados nos Territórios Semiárido Nordeste II (76.245) e Velho Chico (64.994); o Território Sisal (51.804) também foi beneficiado, território que registrava a maior percentual da área ocupada com propriedades familiares, 51,82\%. Territórios que registraram poucos contratos também sofreram forte expansão, como é o caso de Itaparica. Mesmo com a significativa redução do número de contratos assinados no segundo mandato de Lula (20072010), os Territórios Semiárido Nordeste II (48.514), Sisal (33.774) e Velho Chico (27.945) permaneceram como os mais favorecidos. Nos dois governos de Dilma o número de contratos continuou se ampliando, sendo os Territórios Semiárido Nordeste II e Sisal os mais contemplados (TABELA 2). 
Tabela 2 - Contratos Pronaf firmados nos Territórios da Cidadania do estado da Bahia, entre os governos de FHC e Dilma Rousseff/Temer

\begin{tabular}{|c|c|c|c|c|c|}
\hline \multicolumn{6}{|c|}{ Contratos Pronaf (unidades) } \\
\hline $\begin{array}{c}\text { Territórios/Contratos } \\
\text { Pronaf }\end{array}$ & $\begin{array}{l}\text { 2o Mandato FHC } \\
\text { (1999 a 2002) }\end{array}$ & $\begin{array}{c}\text { 1o Mandato } \\
\text { Lula (2003 a } \\
\text { 2006) }\end{array}$ & $\begin{array}{c}\text { 2o Mandato } \\
\text { Lula (2007 a } \\
2010) \\
\end{array}$ & $\begin{array}{c}\text { 1o Mandato } \\
\text { Dilma (2011 a } \\
\text { 2014) }\end{array}$ & $\begin{array}{l}\text { 2o Mandato } \\
\text { Dilma/Temer } \\
\text { (2015 a 2018) }\end{array}$ \\
\hline Baixo Sul & 2.787 & 12.463 & 15.545 & 30.795 & 29.426 \\
\hline Chapada Diamantina & 5.917 & 46.714 & 22.347 & 42.065 & 38.896 \\
\hline Irecê & 4.760 & 31.930 & 21.967 & 31.273 & 32.296 \\
\hline Itaparica & 908 & 15.536 & 5.568 & 10.234 & 5.874 \\
\hline Litoral Sul & 1.225 & 25.560 & 20.248 & 17.780 & 13.280 \\
\hline S. Nordeste II & 31.128 & 76.245 & 48.514 & 74.282 & 60.036 \\
\hline S. S. Francisco & 6.001 & 33.254 & 23.919 & 45.598 & 41.245 \\
\hline Sisal & 7.232 & 51.804 & 33.774 & 62.615 & 63.342 \\
\hline Velho Chico & 40.753 & 64.994 & 27.945 & 43.453 & 35.174 \\
\hline \multicolumn{6}{|c|}{ Contratos Pronaf por estabelecimento da agricultura familiar (unidades) $*$} \\
\hline $\begin{array}{c}\text { Territórios/Contratos } \\
\text { Pronaf }\end{array}$ & $\begin{array}{c}\text { 2o Mandato FHC } \\
\text { (1999 a 2002) }\end{array}$ & $\begin{array}{c}\text { 1o Mandato } \\
\text { Lula (2003 a } \\
2006)\end{array}$ & $\begin{array}{c}\text { 2o Mandato } \\
\text { Lula (2007 a } \\
2010)\end{array}$ & $\begin{array}{c}\text { 1o Mandato } \\
\text { Dilma (2011 a } \\
\text { 2014) }\end{array}$ & \begin{tabular}{|l|} 
2o Mandato \\
Dilma/Temer \\
(2015 a 2018)
\end{tabular} \\
\hline Baixo Sul & 0,11 & 0,51 & 0,63 & 1,25 & 1,20 \\
\hline Chapada Diamantina & 0,18 & 1,44 & 0,69 & 1,30 & 1,20 \\
\hline Irecê & 0,14 & 0,92 & 0,63 & 0,90 & 0,93 \\
\hline Itaparica & 0,08 & 1,31 & 0,47 & 0,87 & 0,50 \\
\hline Litoral Sul & 0,08 & 1,65 & 1,31 & 1,15 & 0,86 \\
\hline S. Nordeste II & 0,63 & 1,54 & 0,98 & 1,50 & 1,21 \\
\hline S. S. Francisco & 0,18 & 1,02 & 0,74 & 1,40 & 1,27 \\
\hline Sisal & 0,14 & 1,00 & 0,65 & 1,21 & 1,23 \\
\hline Velho Chico & 1,34 & 2,14 & 0,92 & 1,43 & 1,16 \\
\hline
\end{tabular}

Fonte: Banco Central do Brasil - Bacen.

* Razão entre o número de contratos realizados e o número médio de estabelecimentos agropecuários entre os Censos Agropecuário de 2006 e 2017.

Observando o número de contratos assinados por estabelecimento agropecuário familiar nos TCs do estado da Bahia $^{8}$, é possível verificar que alguns resultados se mantêm e outros divergem. No segundo mandato de FHC (1999-2002), os Territórios Velho Chico e Semiárido Nordeste II foram os de maiores números de contratos por propriedade familiar, 1,34 e 0,63, respectivamente. No primeiro governo de Lula, os Territórios Velho Chico $(2,14)$ e Semiárido Nordeste II $(1,54)$ mantiveram sendo beneficiados com o maior número de contratos assinados por estabelecimentos, mas ao invés do Território Sisal, foi o Território

\footnotetext{
${ }^{8}$ A análise por estabelecimento agropecuário da agricultura familiar tem como objetivo verificar o alcance do Pronaf em cada território. Entretanto, conforme apresentado, para obter o recurso do Pronaf, o agricultor familiar precisa se enquadrar às exigências da Declaração de Aptidão ao PRONAF (DAP).
} 
Litoral Sul $(1,65)$ o terceiro maior contemplado, como resultado da pequena quantidade de propriedades familiares. O mesmo ocorre no segundo mandato de Lula (TABELA 2).

Nas administrações públicas de Dilma os TCs com maiores médias de contratos assinados do Pronaf por estabelecimento variaram entre o primeiro e o segundo mandato. No primeiro governo de Dilma (2011-2014) as maiores médias de contratos firmados foram nos Territórios Semiárido Nordeste II (1,50), Velho Chico $(1,43)$ e Sertão do São Francisco (1,40). No segundo governo de Dilma/Temer (2015-2018) os Territórios Semiárido Nordeste II $(1,21)$ e Sertão do São Francisco $(1,27)$ permaneceram com as maiores; mas, o Território Sisal (1,23), Chapada Diamantina $(1,20)$ e Baixo Sul $(1,20)$ também passaram a acessar volume maior de contratos Pronaf por estabelecimento (TABELA 2).

É necessário avaliar os valores (em R\$) do Pronaf repassados aos TCs baianos, entre os mandatos de FHC e Dilma. Do mesmo modo que ocorreu com o volume de contratos do Pronaf assinados, os valores do Pronaf repassados aos TCs foram significativamente ampliados entre o segundo governo de FHC e o primeiro governo Lula; já no segundo governo Lula os recursos foram reduzidos. Nos governos de Dilma novamente cresceram os repasses do referido programa na grande maioria dos TCs do estado da Bahia (TABELA 3).

No segundo mandato de FHC (1999-2002) os Territórios Velho Chico (R\$ 25.954.088,00) e Semiárido Nordeste II ( $\mathrm{R} \$ 22.434 .773,00)$ foram notadamente os mais contemplados com os recursos do Pronaf. No primeiro governo Lula (2003-2006) os Territórios Semiárido Nordeste II (R\$ 105.095.246,00), Velho Chico (R\$ 87.207.495,00) e Chapada Diamantina ( $\mathrm{R} \$ 60.370 .370,00)$ se destacaram pelos valores recebidos do Pronaf. Mesmo que no segundo mandato do Lula (2007-2010) no geral os valores Pronaf recebidos tenham sidos reduzidos, os Territórios Semiárido Nordeste II (R \$ 113.218.864,00) e Velho Chico (R\$ 52.515.233,00) permaneceram bastante contemplados (TABELA 3).

Foi no primeiro governo Dilma (2011-2014) que os recursos Pronaf voltaram a se ampliar em todos os TCs, sendo os mais beneficiados o Território Semiárido Nordeste II (R\$ 170.723.449,00), Sisal (R\$121.456.569,00) e Velho Chico (R\$104.237.78,00). No segundo governo Dilma (2015-2018) os valores repassados do Pronaf continuaram se expandindo, principalmente para os Territórios Semiárido Nordeste II (R \$ 322.415.634,00), Sertão do São Francisco (R \$ 162.740.749,00), Sisal (R \$ 147.461.851,00); o Território Velho Chico 
permaneceu recebendo valor semelhante $(\mathrm{R} \$ 107.462 .480,00)$. No geral, considerando os cinco governos instituídos, os territórios mais contemplados foram Semiárido Nordeste II e Velho Chico.

\section{Tabela 3 - Valores (R\$) do Pronaf nos Territórios da Cidadania do estado da Bahia,} entre os governos de FHC e Dilma Rousseff/Temer

\begin{tabular}{|c|c|c|c|c|c|}
\hline \multirow[b]{2}{*}{$\begin{array}{c}\text { Territórios/Valores } \\
\text { Pronaf }\end{array}$} & \multicolumn{5}{|c|}{ Valores do Pronaf (R $\$ 1.000$ de 2018) } \\
\hline & $\begin{array}{c}\text { 2o Mandato } \\
\text { FHC (1999 a } \\
\text { 2002) }\end{array}$ & $\begin{array}{c}\text { 1o Mandato } \\
\text { Lula (2003 a } \\
2006)\end{array}$ & $\begin{array}{c}\text { 2o Mandato } \\
\text { Lula (2007 a } \\
2010)\end{array}$ & $\begin{array}{c}\text { 1o Mandato } \\
\text { Dilma (2011 } \\
\text { a 2014) }\end{array}$ & \begin{tabular}{|c|} 
2o Mandato \\
Dilma/Temer \\
$(2015 \mathrm{a}$ \\
$2018)$ \\
\end{tabular} \\
\hline Baixo Sul & 2.863 & 25.767 & 25.804 & 43.138 & 69.611 \\
\hline C. Diamantina & 7.299 & 60.370 & 41.131 & 89.188 & 41.095 \\
\hline Irecê & 3.928 & 34.366 & 27.594 & 54.481 & 104.420 \\
\hline Itaparica & 1.058 & 13.335 & 6.681 & 28.759 & 23.203 \\
\hline Litoral Sul & 1.793 & 34.886 & 22.385 & 33.628 & 41.057 \\
\hline S. Nordeste II & 22.435 & 105.095 & 113.219 & 170.723 & 322.416 \\
\hline S. S. Francisco & 5.360 & 56.451 & 48.450 & 91.909 & 162.741 \\
\hline Sisal & 6.120 & 48.849 & 37.582 & 121.457 & 147.462 \\
\hline Velho Chico & 25.954 & 87.207 & 52.515 & 104.238 & 107.462 \\
\hline \multicolumn{6}{|c|}{ Valores Pronaf por estabelecimento agropecuário familiar ( $\mathrm{R} \$ 1,00$ de 2018$)^{*}$} \\
\hline Baixo Sul & 116 & 1.047 & 1.049 & 1.753 & 2.829 \\
\hline C. Diamantina & 225 & 1.861 & 1.268 & 2.749 & 1.267 \\
\hline Irecê & 113 & 986 & 791 & 1.563 & 2.995 \\
\hline Itaparica & 89 & 1.127 & 565 & 2.432 & 1.962 \\
\hline Litoral Sul & 116 & 2.250 & 1.444 & 2.169 & 2.648 \\
\hline S. Nordeste II & 453 & 2.121 & 2.285 & 3.446 & 6.508 \\
\hline S. S. Francisco & 165 & 1.737 & 1.490 & 2.827 & 5.006 \\
\hline Sisal & 118 & 946 & 728 & 2.351 & 2.855 \\
\hline Velho Chico & 855 & 2.873 & 1.730 & 3.434 & 3.540 \\
\hline \multicolumn{6}{|c|}{ Valores Pronaf por contratos firmados ( $\mathrm{R} \$ 1,00$ de 2018) } \\
\hline Baixo Sul & 1.027 & 2.068 & 1.660 & 1.401 & 2.366 \\
\hline C. Diamantina & 1.234 & 1.292 & 1.841 & 2.120 & 1.057 \\
\hline Irecê & 825 & 1.076 & 1.256 & 1.742 & 3.233 \\
\hline Itaparica & 1.166 & 858 & 1.200 & 2.810 & 3.950 \\
\hline Litoral Sul & 1.464 & 1.365 & 1.106 & 1.891 & 3.092 \\
\hline S. Nordeste II & 721 & 1.378 & 2.334 & 2.298 & 5.370 \\
\hline S. S. Francisco & 893 & 1.698 & 2.026 & 2.016 & 3.946 \\
\hline Sisal & 846 & 943 & 1.113 & 1.940 & 2.328 \\
\hline Velho Chico & 637 & 1.342 & 1.879 & 2.399 & 3.055 \\
\hline
\end{tabular}

Fonte: Banco Central do Brasil - Bacen.

* Razão entre o número de contratos realizados e o número médio de estabelecimentos agropecuários entre os Censos Agropecuário de 2006 e 2017. 
Todavia, torna-se fundamental avaliar os valores Pronaf por estabelecimento agropecuário familiar para entender melhor a distribuição e considerar as características de cada território. Considerando o período 1999 a 2018, no segundo mandato de FHC (19992002) a média de recursos do Pronaf por estabelecimento familiar foi muito aquém em relação aos demais governos. Nessa gestão de FHC, os territórios mais contemplados foram Velho Chico, Semiárido Nordeste II e Chapada Diamantina, onde cada estabelecimento recebeu do programa $\mathrm{R} \$ 855,00 \mathrm{R} \$ 453,00$ e $\mathrm{R} \$ 225,00$, respectivamente (TABELA 3).

Analisando o primeiro mandato de Lula (2003-2006), cada estabelecimento familiar dos Territórios Velho Chico ( $\mathrm{R} \$ 2.873,00)$ e Semiárido Nordeste II (R\$ 2.121,00) acessou recursos do Pronaf em valores superiores aos do período anterior. Nessa análise por estabelecimento, o Território Litoral Sul foi um dos mais beneficiados, recebeu (R\$ 2.250,00), enquanto o Sisal recebeu apenas R\$946,00. No segundo mandato de Lula (20072010), mesmo que os recursos tenham se reduzido, os Territórios Semiárido Nordeste II (R\$ $2.285,00)$ e Velho Chico ( $\mathrm{R} \$ 1.730,00)$ permaneceram com os maiores valores recebidos por estabelecimento familiar, seguidos pelos Territórios Sertão do São Francisco (R \$ 1.490,00) e Litoral Sul (R\$ 1.444,00). Nos dois governos de Dilma os valores repassados do Pronaf foram ampliados em relação à gestão anterior. Novamente, o destaque são os Territórios Semiárido Nordeste II, Velho Chico e Sertão do São Francisco (TABELA 3).

O valor do Pronaf repassado por contrato firmado nos TCs baianos foram estimados na Tabela 3. Neste caso os resultados para algumas gestões apresentam significativas discrepâncias. No segundo mandato de FHC (1999-2002) os maiores valores do Pronaf por contrato foram registrados nos Territórios Litoral Sul ( $\mathrm{R} \$ 1.464,00)$, Chapada Diamantina $(\mathrm{R} \$ 1.234,00)$ e Itaparica ( $\mathrm{R} \$ 1.166,00)$. Nesse mandado, o menor valor por contrato foi para o Território Velho Chico (R\$ 637,00). No primeiro mandato de Lula (2003-2006) foram os Territórios Baixo Sul (R \$ 2.068,00), Sertão do São Francisco (R \$ 1.698,00) e Semiárido Nordeste II $(\mathrm{R} \$ 1.378,00)$ que receberam os maiores valores médios do Pronaf por contrato assinado. No segundo mandato de Lula (2007-2010) os Territórios Semiárido Nordeste II $(\mathrm{R} \$ 2.334,00)$ e Sertão do São Francisco $(\mathrm{R} \$ 2.026,00)$ permaneceram com os maiores valores médios recebidos do Pronaf por contratos, seguidos agora pelo Território Velho 
Chico (R\$ 1.879,00). Ainda no segundo mandato de Lula, o menor valor por contrato foi para o Território Litoral Sul (R\$1.107,00)

Exceto no Território Chapada Diamantina, nos dois mandatos de Dilma os recursos do Pronaf por contratos firmados foram ampliados em todos os TCs baianos, principalmente no segundo governo. Diferente das administrações públicas anteriores, nas gestões de Dilma o Território Itaparica se destaca pelos recursos recebidos do Pronaf por contrato. O Território Semiárido Nordeste II também foi bastante contemplado, além do Território Velho Chico e Sertão do São Francisco. Entretanto, as discrepâncias de valores se mantiveram. Considerando o valor médio de contrato no segundo governo Dilma, enquanto o Território Semiárido Nordeste II registrou R \$ 5.370,00, no Sisal o valor foi de R \$ 2.328,00.

Sendo assim, durante a execução do Pronaf entre os governos FHC e Dilma, instituídos entre 1999 e 2018, pode-se notar crescimento do valor total e do valor médio por contrato e concentração de recursos em poucos territórios. Os maiores valores totais ou valores por contrato Pronaf firmado ocorreram nos Territórios Semiárido Nordeste II, Velho Chico e Sertão do São Francisco. Considerando os dados do segundo Governo Dilma, o Território Semiárido Nordeste II abocanhou isoladamente 31,6\% do total de Pronaf liberado para os nove territórios analisados (TABELA 3).

\section{CONSIDERAÇÕES FINAIS}

O presente trabalho buscou discutir a execução do Pronaf nos TCs do estado da Bahia durante os últimos vinte anos. No período, entre 1999 e 2018, o Brasil passou pelos mandatos de FHC, Lula e Dilma/Temer, cujos gestores públicos se denominavam social-democratas ou neoliberais. Assim, verificou-se que houve contradições no planejamento dos cinco governos (designadamente na elaboração dos Planos Plurianuais) e na operacionalização do crédito rural via Pronaf. Este passou por alterações praticamente anuais quando as linhas e os critérios para adesão foram modificados visando ampliar o acesso, todavia mantendo o objetivo de apoiar o produtor familiar presente em diversas regiões do país.

Os resultados da pesquisa apontam que os nove TCs baianos são heterogêneos quanto ao número e, principalmente, quanto à área pertencente aos estabelecimentos agropecuários familiares. Os Territórios Irecê, Sertão do São Francisco, Semiárido Nordeste II, Chapada 
Diamantina, Itaparica e Velho Chico, registraram acima de $80 \%$ de propriedades do tipo familiar. Em si tratando da área ocupada, a participação dos estabelecimentos agropecuários familiares supera os $36 \%$ em oito territórios, dos quais em quatro aproxima-se dos $50 \%$ (Sisal, Itaparica, Sertão do São Francisco e Semiárido Nordeste II). A exceção é o Território Litoral Sul $(28,25 \%)$, ainda sim, maior que o percentual nacional.

Entre 1999 e 2018 os recursos (volume de contratos e valor total) do crédito rural via Pronaf distribuídos aos nove TCs da Bahia foram crescendo. O grau de cobertura foi se ampliando ao longo da trajetória analisada. No primeiro período (segunda gestão de FHC), a cobertura não chegava a um terço dos estabelecimentos; o crédito Pronaf foi ampliado no primeiro Governo Lula, porém reduzido no seu segundo mandato. A cobertura do Pronaf voltou a crescer nos governos Dilma, quando o número de contratos superou o número de estabelecimentos da agricultura familiar. Todo este comportamento foi demonstrado por Bianchini (2015) ao analisar o cenário nacional.

Comumente, os TCs mais beneficiados permaneceram os mesmos nas diferentes administrações públicas, com poucas exceções, situação que demonstra a manutenção da concentração de recursos do Pronaf. Considerando os cinco governos, de FHC à Dilma/Temer, e o total de contratos e de valores Pronaf, os TCs mais contemplados foram Semiárido Nordeste II, Sisal e Sertão São Francisco. Juntos, os três territórios receberam 62\% dos recursos destinados aos nove TCS analisados no segundo mandato de Dilma. Avaliando o valor por estabelecimento e o valor por contrato firmado, foram mais agraciados os TCs Semiárido Nordeste II, Velho Chico e Sertão do São Francisco.

Cabe salientar que o maior volume de recursos Pronaf deveria ter sido acessado pelos Territórios Irecê, Chapada Diamantina e Itaparica, cada um com mais de $80 \%$ ou $90 \%$ do número de estabelecimentos familiares ou mais de $50 \%$ da área pertencente a agricultores familiares. Ademais, não é possível explicar por que o Território Litoral Sul (de reduzido número de estabelecimentos e de área da agricultura familiar) teve grande acesso ao Pronaf nas administrações de FHC e Lula.

É importante ressaltar o baixo valor de cada contrato do Pronaf nos TCs baianos. Considerando o período do segundo mandato de Dilma/Temer (2015-18), na média cada contrato do Pronaf foi de R\$ 3.190,00; valor inferior ao R\$3,500,00 encontrado por 
Bianchini (2015) ao analisar todo o Nordeste para a Safra 2014/15; enquanto a média nacional foi de R \$25.173,00. Impressiona o caso do Território Chapada Diamantina, com mais de 41 mil contratos e o valor médio de apenas $\mathrm{R} \$ 1.057,00$. Tais dados confirmam a análise de Batista da Silva et al (2017), da grande quantidade de contratos de Pronaf no Nordeste, porém com baixos valores, muito em função da predominância da linha de microcrédito de investimento do Pronaf B.

Portanto, ao constatar o baixo valor por contrato (insuficiente para promover significativo aumento de produção, produtividade e renda), aliando a concentração de recursos do Pronaf aplicados em poucos territórios e a discrepância de valores, seja por estabelecimento ou por contrato, a política de crédito rural realizada na Bahia, embora seja importante para cada família de agricultor familiar beneficiado, não reduz as diferenças socioeconômicas existente entre os agricultores e entre os diferentes territórios do estado. Pelo contrário, em alguns casos, pode até ampliar tais diferenças, o que vai em desencontro com o objetivo geral da política de desenvolvimento territorial rural, que é a de reduzir as desigualdades locais e regionais. Espera-se que estas informações possam provocar novas pesquisas, e subsidiar discussões e decisões de toda a sociedade civil e do poder público.

\section{REFERÊNCIAS}

ACCARINI, J. H. Economia rural e desenvolvimento: reflexões sobre o caso brasileiro. Petrópolis: Vozes, 1987.

ARBAGE, Alessandro Porporatti. Fundamentos de economia rural. Chapecó: Argos, 2012.

BACEN. Banco Central do Brasil. Manual do Crédito Rural. 2013. Disponível em: https://www3.bcb.gov.br/mcr. Acesso em: 14 de dez. de 2018.

BATISTA DA SILVA, D. M. O.; SCHIMIDT FILHO, R.; AGUIAR, M. B. M.; COSTA, F. B. PRONAF: uma avaliação da distribuição regional dos contratos de crédito e seus impactos sobre o desenvolvimento rural do Nordeste brasileiro. Geografia em debate: v.11 n.2 p. 376-396. 2017.

BIANCHINI, V. Vinte Anos do PRONAF, 1995-2015: avanços e desafios. Brasília: SAF/MDA, 2015.

BRASIL. Ministério do Planejamento, Orçamento e Gestão. Secretaria de Planejamento e Investimentos Estratégicos. Plano Plurianual 2016-2019: Desenvolvimento, produtividade e inclusão social - mensagem presidencial. Brasília (DF), 2015. 
Ministério do Planejamento, Orçamento e Gestão. Secretaria de Planejamento e Investimentos Estratégicos. Plano Plurianual 2012-2015:Plano mais Brasil, mais desenvolvimento, mais igualdade, mais participação - mensagem presidencial. Brasília (DF), 2011

Presidência da República. Casa Civil. Subchefia para Assuntos Jurídicos. Decreto de 25 de fevereiro de 2008 (Institui o Programa Territórios da Cidadania e dá outras providências). 2008.

Ministério do Planejamento, Orçamento e Gestão. Secretaria de Planejamento e Investimentos Estratégicos. Plano Plurianual 2008-2011:Desenvolvimento com inclusão social e educação de qualidade - mensagem presidencial (volume I). Brasília (DF), 2007

Ministério do Planejamento, Orçamento e Gestão. Secretaria de Planejamento e Investimentos Estratégicos. Plano plurianual 2004-2007: Plano Brasil de todos: participação e inclusão - projeto de lei. Brasília (DF), 2003.

Congresso Nacional. Plano plurianual 2000-2003: Diretrizes estratégicas e macroobjetivos - Anexo I. Brasília (DF), 1999.

GIL, A C. Métodos e técnicas de pesquisa social. São Paulo: Atlas, 2018.

GRISA, C.; WESZ JUNIOR, V. J.; BUCHWEITZ, V. D. Revisitando o Pronaf: velhos questionamentos, novas interpretações. Revista de Economia e Sociologia Rural. 2014, vol.52, n.2, pp.323-346.

IBGE. Instituto Brasileiro de Geografia e Estatística. Censo Agropecuário 2006.

Disponível em:<https://sidra.ibge.gov.br/pesquisa/censo-agropecuario/censo-agropecuario2006/segunda-apuracao>. Acesso em 01 de maio de 2020a.

Instituto Brasileiro de Geografia e Estatística. Censo Agropecuário 2017.

Disponível em: <https://sidra.ibge.gov.br/pesquisa/censo-agropecuario/censo-agropecuario2017>. Acesso em 10 de maio de 2020b.

ORTEGA, A. C.; JESUS, C. M.; SILVA SO, L. L. O PAA-leite na Bahia e em Minas Gerais: Uma avaliação preliminar de seus modelos de implementação. In: Flavio Borges Botelho Filho. (Org.). Avaliação das Políticas Públicas Rurais. Brasília: UNB, 2006, v. 24, p. 57-89.

ORTEGA, A. C. Territórios deprimidos: desafios para as políticas de desenvolvimento rural. Campinas: Alínea; Uberlândia: Edufu, 2008.

PRZEWORSKI, A. Capitalismo e social-democracia. São Paulo, Companhia das Letras, 1995.

\section{RAMOS, S. Y.; MARTHA JÚNIOR, G. B. Evolução da política de crédito rural} brasileira. Planaltina, Distrito Federal (DF): Embrapa Cerrados, 2010.

SCHEJTMAN, A. BERDEGUÉ, J. Desarrollo territorial rural. Rimisp, Santiago/Chile, febrero, 2003. 